\title{
VARIOUS MPPT METHODS TO IMPROVE THE SOLAR PV SYSTEM EFFICIENCY - A REVIEW
}

\author{
${ }^{1}$ B. Lakshmi and ${ }^{2}$ M. S. Sujatha \\ Center for Energy, \\ Department of Electrical and Electronics Engineering, \\ Sree Vidyanikethan Engineering College, India \\ ${ }^{1}$ lakshmi3019@gmail.com, ${ }^{2}$ sujatha.machineni@gmail.com
}

Abstract - In the globe renewable energy generation is increasing now days. Mainly all are focusing on solar energy systems. Maximum Power Point Tracking (MPPT) technique is used commonly with Photo Voltaic solar systems to maximize the power extraction under all conditions. The paper discusses the various methods of MPPT of PV system such as Incremental Conductance (INC), Artificial Neural Network (ANN), Perturb and Observe (P\&O), Partial Swarm Optimization (PSO), Fuzzy Logic Control (FLC) irrespective of natural conditions, for example, (temperature and irradiation). It also illustrates the literature on above methods and its comparison.

Keywords - Photovoltaic, Maximum Power Point Tracking, DC to DC converters

\section{INTRODUCTION}

In power system, renewable energy systems are more important for power generation units. These generation depends on different sources like wind, solar, geothermal, hydel, ocean etc. this sources are freely available in nature, and no pollution in the environment. So, it is eco-friendly in nature. Photovoltaic is the main energy source in the distributed energy sector $[1,2]$.

The PV system performs the transformation of daylight electricity into electric power. The simple operating principle is the similar as PN - junction diode. Photovoltaic system output is inside the shape of fluctuating direct current $\&$ is likely to reinforce transform to stabilize direct current fluctuating voltage and step up to better direct current voltage. The boost converter is connected to the buck converter and then given to the battery. The use of strength of electronic gadgets together with MPP controller can build the effectiveness of the PV structure. MPPT can significantly increase the performance of the photovoltaic system $[3,4]$.

\subsection{PHOTOVOLTAIC SYSTEM}

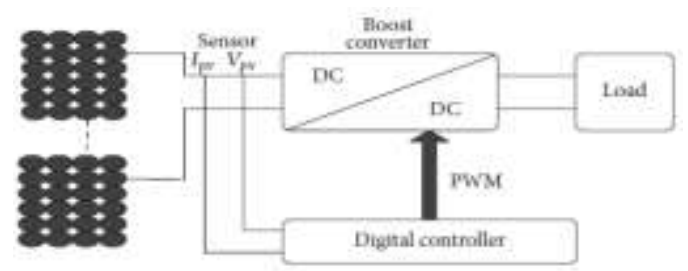

Fig. 1 Photovoltaic generation system [3]

Received: July 18, 2019

Reviewed: December 11, 2019

Accepted: December 15, 2019

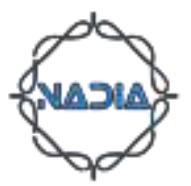


Fig. 1 shows the photovoltaic generation system. By attaching many series and parallel pattern of solar cells, a photovoltaic module is shaped. Photovoltaic modules are linked in series means to obtain maximum output voltage; PV modules are linked in parallel means to obtain maximum output current. A nonlinear characteristic of the photovoltaic array is the major challenge of the photovoltaic power generation system. The characteristics of PV depend on temperature and irradiance [3].

\subsection{PHOTOVOLTAIC PANEL MODEL}

Photovolatic Module is a semi-conductor device with two p-n junction. It converts the source of light into electrical energy. There are resistances and a diode. The parallel resistance represents the loss that small leakages modern flows through the parallel direction, series resistance represents the losses of metal grid, contacts and modern collection bus. Diode is a pass contemporary associated with $\mathrm{p}-\mathrm{n}$ junction and semiconductor gadgets.

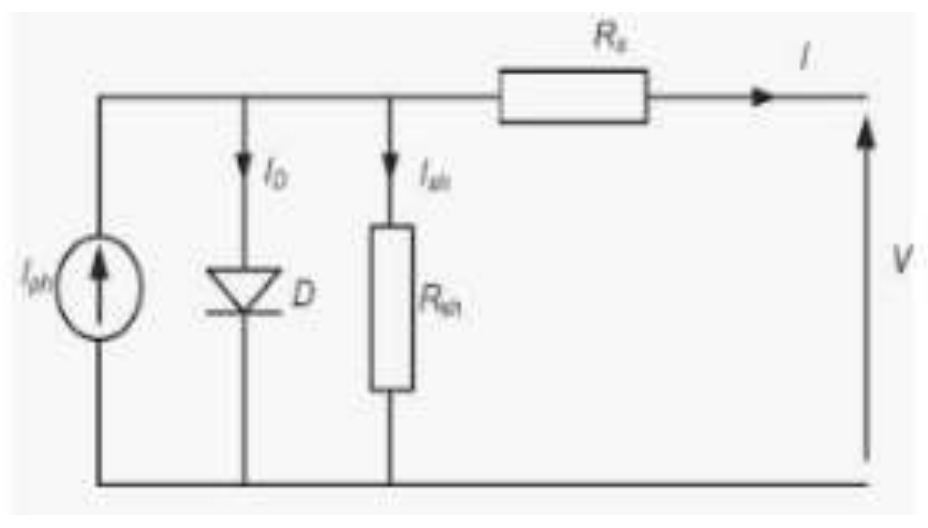

Fig. 2 Single diode model of Photovoltaic cell [18]

Fig. 2 shows the single diode model of photovoltaic cell equivalent circuit [18]. Characteristic equation is developed on the basis of the equivalent circuit. The current or photo current generated by light varies with irradiance and temperature is given by the following mathematical equation.

$I=I p h-I s\left[\exp \frac{(V+I R s) q}{a k T N s}-1\right]-\frac{V+I R s}{R s h}$

Where, I ph $=$ Photo current generated in cell

Is $=$ Saturation current

$\mathrm{T}=$ Temperature

$\mathrm{Rs}=$ Resistance in series

$\mathrm{Rsh}=$ Resistance in shunt

$\mathrm{K}=$ Boltzman constant

Ns $=$ Number of series cells

$\mathrm{a}=$ Ideality factor

$q=$ Electron charge 


\section{MAXIMUM POWER POINT TRACKING}

Tracking of the Maximum Power Point (MPP) of a Photovoltaic (PV) array is usually an essential task in PV systems. In general, PV generation systems have two major problems. Conversion efficiency of electric power generation is low and the amount of electric power generated by solar arrays changes continuously with weather conditions. Efficiency of power transfer from solar cell depends on the amount of sun light falling on the solar panels and also the electrical characteristics of load. As the sun light varies, the load characteristics that gives highest power transfer efficiency changes. Further, the feature of the solar cell is nonlinear and changes with irradiation \& temperature. There may be a completely unique point at the solar array's current - voltage or power - voltage curve called MPP at which the whole PV system (array, converter, etc...) works with high efficiency and produces high output power. Many maximum power point tracking algorithms are using to increase power transfer efficiency. But most of the present maximum power point tracking algorithms suffers from slowly monitoring, which reduces the performance of use.

\section{DC TO DC CONVERTER}

DC - DC converter is an electronic circuit or electromechanical instrument that changes over a quick modern-day supply starting with one voltage level then onto the next. It's a kind of step - up / step - down converter.

\subsection{BOOST CONVERTER}

It is an energy electronic device that converts over yield voltage is superior to the enter voltage. Fig. 3 suggests the boost converter circuit diagram which includes voltage source, inductor, capacitor and load [18].

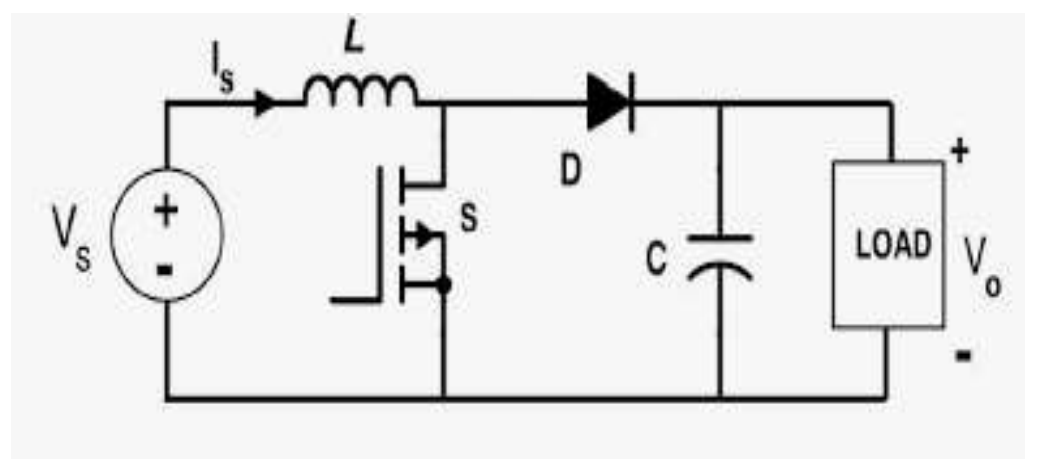

Fig. 3 Basic converter boost circuit [18]

The DC - DC boost converter is used to improve the output power of the PV array. The operation of boost converter is controlled by a suitable controller based on the output voltage and current of PV array. Here $\mathrm{Vo} / \mathrm{Vs}=1 /(1-\mathrm{D})$ is the proportion of output voltage to enter voltage. Step - up converter with two operating modes: Continuous Conduction mode \& Discontinuous Conduction Mode. Inductance and capacitance values will decide the mode of operation. The inductance value is bigger than the $\mathrm{L}$ - critical then the step up converter works in Continuous Conduction Mode (CCM). The capacitance value limits the ripple in the yield voltage.

\section{REVIEW OF LITERATURE}

The following literature provides the outline and relevance of each technique in improving the efficiency of the PV system. 


\section{A. INCREMENTAL CONDUCTANCE}

INC technique determines the path and voltage of radiation which changes swiftly under converting conditions. It addition to this, it calculates the maximum power point.

Umashankar .S, Punna Srikanth and D. Vijay Kumar et. al., in 2011 [1] discussed the comparative study of incremental conductance and perturb \& observe MPPT algorithm and analyzed different combinations of DC to DC converters. The photovoltaic gadget performance is low. These approaches vary in many ways which include cost, simplicity and speed etc. The main advantage of this technique is good performance under swiftly changing situations. Disadvantage of this approach output power oscillations are more.

In 2004, Cheung, Liu et. al., [2] has discussed the INC algorithm is to find the derivative of photovoltaic electricity regarding its leaving voltage, that is $\mathrm{dP} / \mathrm{dV}$. $\mathrm{dP} / \mathrm{dV}$ processes 0 , it generates higher electricity. The controller computes $\mathrm{dP} / \mathrm{dV}$ fundamentally dependent on estimated PV gradual output power and voltage. If $\mathrm{dp} / \mathrm{dv}$ isn't always near 0 , the controller will alter the voltage until $\mathrm{dp} / \mathrm{dv}$ approaches 0 ; PV array achieves its more output. The main advantage of this algorithm is speedy monitoring, drawback is low isolation ranges and results are inaccurate.

Larbes, M. S. Ait Cheikh et. al., [3] in 2007 has mentioned an intelligent control technique for the MPP monitoring of photovoltaic machine under change in temperature and insolation situations. Some control schemes had just been utilized and had proven a few defects, some other methods to optimize the output. The main drawback of this strategy is change efficiency of PV module is less and advantage of intelligent control procedure utilizing fuzzy logic control to improve performance.

T. Esramand, P. L.Chapman et. al., [4] has discussed the comparison of fractional open circuit voltage and short out voltage of photovoltaic exhibit MPPT approach in 2013. These strategies are various in convergence speed, complexity, cost, etc. This strategy is working primarily dependent on slope of photovoltaic array curve. The MPP can track based on the instant conductance to the incremental conductance.

In 2013 Trishan Esram, Patrick L. Chapman and Liu et. al., [5] has discussed comparison of hill climbing and Incremental conductance algorithm of PV exhibit by MPP techniques. It utilizes variable voltage step length to evaluate dynamic reaction and steady state oscillations relative to step length. This decreases oscillations and improves the photovoltaic power system's converter energy performance.

M. Adly M. Ibrahim and H. El Sherif et. al., [6] has discussed an improved energy generation expansion methods for PV system approach in 2013. It examined INC for photovoltaic models beneath hastily changing environmental conditions by utilizing the DC to DC converter. As an isolation level via the load - linked photovoltaic, at the required maximum power point voltage and saving energy extraction losses of 15 percent.

Moacyr A. G. de Brito, Leonardo P. Sampaio et. al., [7] in 2014 explained the comparative analysis of voltage ripple and dynamic response of MPPT strategies for PV applications. The fundamental maximum power point tracking strategies are below stable conditions as well as varying environmental situations. The main advantage of INC gives good dynamic performance in terms of changing weather conditions. Disadvantage of this method is complex to implement with two sensors in terms of efficiency and power loss.

In 2014 M. Saad Saoud et. al., [8] explained an improved incremental conductance technique for MPPT utilizing cuk converter to track rapidly varying irradiance conditions with higher accuracy. It adjusts the duty cycle according to the working factor of the PV array. The main disadvantages are the high cost of implementation and complexity.

\section{B. PERTURB AND OBSERVE METHOD}

This algorithm is the most typically utilized in photovoltaic systems applications, due to its easy implementation and simplicity. It's an iterative approach for obtaining the 
MPP. It measures a photovoltaic module current and voltage, and then perturbs the operating point of a photovoltaic module to determine the exchange of path.

A. Patel, V. Kumar, and Y. Kumar et. al., [9] in 2014 defined the P \& O MPPT for photovoltaic device's to maximize the photovoltaic exhibit output power by tracking consistently the MPP, which depends on panel's temperature and irradiance situations. The main advantage of this method is easy implementation. The main disadvantages are operating point oscillates and steady state error around the MPP offering rise to the misuse of energy and slows down the speed response.

In 2013 T. H. Tuffaha, M. Babar, Y. Khan and N. H. Malik et. al., [10] have mentioned the investigation of $\mathrm{P}$ and $\mathrm{O}$ and Modified perturb \& observe algorithm. $\mathrm{P}$ and $\mathrm{O}$ algorithm works by way of periodically perturbing, that is accelerates or decelerates. If the photovoltaic array working voltage adjustments then energy will increase, the control machine moves in same path. Modified perturb and observe technique was proposed to solve the oscillation issue with aid of decoupling the PV energy fluctuations caused by climbing process. It is simple and reliable technique.

C. Liu, B. Wu and R. Cheung et. al., [11] in 2014 has proposed decoupling the photovoltaic electricity fluctuations, due to the Climbing Perturb \& Observe process from the difference of the irradiance to resolve the oscillation trouble. The INC alternate control change in power is calculated. If the value is tremendous, the running voltage is improved to get maximum power point: If the esteem is -ve, the voltage adjustment direction is reversed $\&$ the working factor in looking to make it the nearest to maximum power point.

In 2015 Y. Jung, G. Yu, and J. Choi et. al., [12] have discussed an improved P \& O technique with adaptive set of rules, to regulate the reference voltage at slow varying atmospheric situations to decrease the photovoltaic output power. This method is also eliminates oscillation problems and improves speed based on power value. The main disadvantage of this method is more investment cost and low performance.

Sony Venugopal and Akshay S Aspalli et. al., [13] in 2017 have modeled and analyzed the PV gadget to maximise photovoltaic array output power by using constant tracking MPP. The most energy extracted from the photovoltaic source based totally on load, temperature and irradiation. If there is a good irradiance situation, it generates high power efficiently.

\section{PSO BASED MPPT TECHNIQUES}

PSO is a population based stochastic optimization technique. It operates two modes: swarming habits of animals and Evolutionary computation.

V. Das, P. Karuppanan and A. K. Singh et. al., [14] have discussed a grid connected and off - grid solar photovoltaic system in 2018. The photovoltaic gadget operates in grid linked mode of operation. While sun PV system operates in off-grid mode to satisfy the load and identify the alternative energy source based totally on hybrid grid - tied electricity supply. This technique is more reliable. The main drawback of this technique is power quality problems.

In 2014 M. Abdulkadir, A. H. M. Yatim, and S. T. Yusuf et. al., [15] have discussed an improved particle swarm optimization based MPPT control strategy for PV system. It explained the energy loss because of partial shading \& minimization with the aid of dividing the photovoltaic machine into a number of little arrays. If the wide variety of modules accelerates, the characteristics are subjected to uneven insulations; if one module is totally illuminated $\&$ the alternative one is partially shaded. The main advantage of this technique is fast changing situations and more reliable.

K. Ishaque, Z. Salam,M. Amjad, and S.Mekhilef et. al., [16] in 2017 has discussed an improved particle swarm optimization based maximum power point tracking with reduced steady state oscillations for photovoltaic system. In this strategy the usages of evolutionary algorithm technique with non-linear objective function. When the MPP is 
found, it reduces the oscillations. The main drawback of this technique is large fluctuations.

Y. H. Liu, J. W. Huang and W. C. Liang et. al., [17] have discussed particle swarm optimization based maximum power point tracking for partially shaded PV arrays in 2012. During partial shaded condition, the power -voltage curves of photovoltaic will become extra complicated with more than one MPP. Maximum power point can extract irrespective of the dynamic environmental modifications, which include temperature and irradiance. These approaches can carry out excessive solar irradiance but the tracking efficiency will drop extensively.

In 2012 Lin and Liang et. al., [18] have discussed the particle swarm optimization based PI controller design for a sunlight based charger system. The solar charge incorporated system only attentions on load charge control or switching MPPT. This approach is utilized in two - level system, which permits the general sun energy charging device to actualize maximum power point tracking. The charging machine makes use of constant current or constant voltage approach to charge battery.

Tianmeng Wei, Dongliang Liu and Chuanfeng Zhang et. al., [19] in 2014 explained MPPT technique based on modified PSO for PV system. The particle swarm optimization has simple shape, smooth implementation and rapid computing functionality. It's able to discover the maximum power point for any form of photovoltaic curve regardless of environmental changes \& reduced PSO search space and the time required for convergence may be significantly reduced. Drawback of this technique is low dynamic response speed.

\section{ANN BASED MPPT TECHNIQUES}

A multilayer neural back propagation network with trained network feedback is used in this technique. A two level offline trained ANN based MPPT with two cascaded ANNs; estimates the temperature \& irradiance levels from the voltage of the photovoltaic array and current alarms. This approach offers good performance for both steady state and transient conditions even below rapidly converting environmental situations.

L. L. Jiang, D. R. Nayanasiri, D. L. Maskell, and D. M. Vilathgamuwa et. al., [20] in 2013 explained a straightforward and effective hybrid MPPT technique for photovoltaic systems under partial shaded conditions. The main strategy of this approach is to increase the electricity output from photo - voltaic structure. The device is capable of accurately decide the global MPP and increase the energy output from the PV array. In this approach as exceptionally decrease cost and easy implementation. The main disadvantage of this technique is increased power loss.

In 2014 L. M. Elobaid, A. K. Abdelsalam, and E. E. Zakzouk et. al., [21] provided the ANN - based maximum power point tracking with two - stage technique for MPP; ANN algorithm is independent of time dependence to track the maximum power point and change the PV characteristics. The characteristics of PV are nonlinear. To overcome the nonlinear characteristics of the PV array by using Differential Evolution \& Artificial Neural Network together with traditional MPPT to track the MPP.

R. Ramaprabha, M. Sharanya et. al., [22] have discussed an artificial neural network based maximum power point tracking for photovoltaic system approach in 2009. To estimate the temperature \& irradiance levels from exhibit voltage and current sign to decide the optimum peak working point. This technique gives better performance for both steady state \& transient instants even beneath swiftly changing environmental situations.

S. D. Anitha and S. B. J. Prabha et. al., [23] in 2016 explained the modeling of MPPT strategies for PV system under varying situations, it generate more power with irrespective of I - V curves of load. The PV system's ANN - based maximum power point tracking controller to overtake the drawback of slowly tracking. ANN operates at maximum point $\&$ reduced oscillations with the help of step up converter. 


\section{E. FUZZY LOGIC CONTROLLER (FLC) BASED MPPT TECHNIQUES}

Fuzzy logic controller is developed based on human thinking and natural activities. It does not need accurate data and knowledge to train the system. If any new rules are added, no need to train the system. Implementation of FLC is easy and flexible. It could handle non - linear characteristics, however it offers accurate effects.

In 2014 Abu-Rub and Ahmed et. al., [24] has implemented an adaptive fuzzy inference system based MPPT of a sun photovoltaic module. A fuzzy logic controller - based MPPT method to track high power under quickly varying conditions compared to conventional algorithms. In this technique electrical power efficiency is low under less irradiance conditions.

Chiu and Ouyang et. al., [25] has discussed a novel two-mode MPP control algorithm in 2015. This technique is based on comparative study of consistent voltage control and incremental conductance technique. It offered the most energy with rapid reaction in the available sun irradiance \& temperature. Here MPPT is used to adjust the voltage of photovoltaic modules by varying the boost converter duty ratio. The insolation intensity is less than thirty.

Khaled Bataineh, Yazan Taamneh et. al., [26] in 2017 has discussed adaptive neuro fuzzy inference system based improvement of P \& O MPPT strategy for PV systems. The PV system depends on shading and different conditions. The tracking algorithm depends on direct and indirect techniques such as quasi seeking and true measurements. Advantage of this method is more accuracy and fewer oscillations. In this technique has poor performance for partial shaded conditions.

R. Vinifa and A. Kavitha et. al., [27] explained the MPPT of step - up converter on a photovoltaic system utilizing fuzzy logic approach in 2017. The energy extraction from these assets needs to be operated in most useful operating point. Here Maximum Voltage and Power based controls are utilized to control the output photovoltaic voltage from MPP. Fuzzy logic controller overcomes the drawbacks of nonlinearity of PV output due to temperature and irradiation changes. Drawback of this technique is difficult to maintain more power for all situations.

In 2018 Unal Yilmaz and Ali Kircay et. al., [28] has discussed the photovoltaic system fuzzy logic MPPT strategy and PI as a charge controller. Fuzzy Logic Control MPPT technique was preferred in this steady, to increase the efficiency and decrease the payback period of the gadget because it's rapid reaction to converting environmental situations and isn't tormented by converting circuit parameters. This operates photovoltaic panel at MPP under variable environmental situations to increase efficiency, decrease cost and increase life cycle.

\section{COMPARATIVE ANALYSIS AND DISCUSSION}

Table I displays the comparative analysis of different techniques. This paper discusses the various research studies to find the MPPT efficiency of photovoltaic system. It is difficult to obtain accurate comparisons applying different techniques. However, with some of the solutions error and complexity can be reduced. A few techniques such as P\& O method, Incremental conductance, and particle swarm optimization have some limitations. P \& O method has more oscillations, Incremental conductance technique performs moderate efficiency and low speed and particle swarm optimization method gives low dynamic response. It is observed that ANN, FLC and PSO perform well with respect to tracking speed and overall efficiency compared to P \& O and INC methods. Further applying ANN, FLC and PSO techniques, steady state error and static error can be reduced. Fuzzy logic controller has better response with accurate results, less complexity and high tracking speed (static and dynamic) with improved efficiency. 
Table I. Comparative Analysis of Different Techniques

\begin{tabular}{|l|l|l|l|l|l|}
\hline Item & P \& O & INC & ANN & FLC & PSO \\
\hline Steady state oscillation & Large & Moderate & Zero & Zero & Zero \\
\hline Static error & High & High & Low & Low & Low \\
\hline Temperature characteristics & Poor & Poor & Good & Good & Good \\
\hline Dynamic response & Poor & Medium & High & High & Poor \\
\hline System complexity & Simple & Simple & Medium & Medium & Simple \\
\hline Tracking speed & Slow & Slow & Moderate & Fast & Fast \\
\hline Overall efficiency & Medium & Medium & High & High & High \\
\hline Commutation & More & More & Medium & Moderate & Less \\
\hline
\end{tabular}

\section{CONCLUSION}

This paper presents the overview and key issues of various research studies for different MPPT methods used in solar photovoltaic systems. It started with introduction of most important MPPT techniques and literature of different author's papers were discussed. Main characteristics were highlighted in comparison table. It is evident that on the analysis of various methods ANN and FLC are comparatively better methods for MPPT. To overcome the drawbacks in P \& O, INC and PSO, Fuzzy logic controller is applied to increase the efficiency, minimize the cost and also maintains constant voltage for battery.

\section{REFERENCES}

[1] Umashankar .S, Punna Srikanth and D. Vijay Kumar "Comparative study of maximum power point tracking algorithms," International Research publication, vol. 3, no. 1, pp. 11-20, 2011.

[2] C. Liu, B. Wu, and R. Cheung, "Advanced algorithm for MPPT control of photovoltaic systems," in Proceedings of the Canadian Solar Buildings Conference, Canadian Solar Buildings Conference Montreal, August 2004, pp. 20-24.

[3] S. Ait Cheikh, C. Labres, G. F. Tchoketch Kebir, and A. Zerguerras, "Maximum power point tracking using a fuzzy logic control scheme,” Revue des Energies Renouvelables, vol. 10, pp. 387-395, 2007.

[4] T. Esramand P. L.Chapman, "Comparison of photovoltaic array maximum power point tracking techniques," IEEE Transactions on Energy Conversion, vol. 22, no. 2, pp. 439-449, 2013.

[5] Trishan Esram, Patrick L. Chapman and Liu, "Comparison of photovoltaic array maximum power point tracking techniques," in IEEE Transactions on Energy Conversion, pp. 1-6, Vol. 22, 2013.

[6] M. Adly, M. Ibrahim and H. El Sherif, "Comparative study of improved energy generation maximization techniques for photovoltaic system," in proceedings of the Asia-Pacific Power and Energy Engineering Conference (APPEEC), pp.1-5, March 2013.

[7] A. F. Murtaza, H. A. Sher, M. Chiaberge, D. Boero, M. De Giuseppe, and K. E. Addoweesh, "Comparative analysis of maximum power point tracking techniques for PV applications," in Proceedings of the 16th International Multi Topic Conference (INMIC '13), pp. 83-88, IEEE, Lahore, Pakistan, May 2014.

[8] Merwan Saad Saouq, Hadj Ahmad Abbassi, Salem Kermiche, "Improved incremental conductance method for MPPT using cuk converter", WSEAS Trans. Power systems, vol. 8, 2014.

[9] A. Patel, V. Kumar, and Y. Kumar, "Perturb and observe maximum power point tracking for Photovoltaic cell,” Innovative Systems Design and Engineering, vol. 4, no. 6, pp. 9-15, 2014.

[10] T. H. Tuffaha, M. Babar, Y. Khan, and N. H. Malik, "Comparative study of different hill climbing MPPT through simulation and experimental test bed," Research Journal of Applied Sciences, Engineering and Technology, vol. 7, no. 20, pp. 4258-4263, 2013.

[11] C. Liu, B.Wu, and R. Cheung, "Advanced algorithm for MPPT control of photovoltaic systems," in Proceedings of the Canadian Solar Building Conference, Montreal, Canada, August 2014.

[12] Y. Jung, J. So, G. Yu, and J. Choi, "Improved perturbation and observation method (IP\&O) of MPPT control for photovoltaic power systems," in Proceedings of the 31st IEEE Photovoltaic Specialists Conference, pp. 1788-1791, IEEE, Lake buena Vista, Fla, USA, January 2015.

[13] A. Sony venugopal and Akshay S Aspalli, "Maximum power point tracker for a photovoltaic system," Proc. of Int. Conf. on Current Trends in Eng., Science and Technology, ICCTEST), pp. 463-465, March 2017.

[14] V. Das, P.Karuppanan, A.K.Singh "Grid-connected and off-grid solar pv system," smart energy grid design for island countries, pp.125-157, 2018. 
[15] M. Abdulkadir, A. H. M. Yatim, and S. T. Yusuf, "An improved PSO-based MPPT control strategy for photovoltaic systems," International Journal of Photoenergy, vol. 2014, Article ID 818232, 11 pages, 2014.

[16] K. Ishaque, Z. Salam,M. Amjad, and S.Mekhilef, "An improved particle swarm optimization (PSO)based MPPT for PV with reduced steady-state oscillation," IEEE Transactions on Power Electronics, vol. 27, no. 8, pp. 3627-3638, 2017.

[17] Y.H. Liu, S.C. Huang, J.W. Huang, and W.-C. Liang, "A particle swarm optimization based maximum power point tracking algorithm for PV systems operating under partially shaded conditions," IEEE Transactions on Energy Conversion, vol. 27, no. 4, pp. 1027-1035, 2012.

[18] Her-Terng yau, C.J. Lin, and Q.C. Liang, "PSO based PI controller design for a solar charger system," The Scientific World Journal, vol. 2013, Article ID815280, 13 pages, 2012.

[19] Tianmeng Wei, Dongliang Liu, Chuanfeng Zhang. "An improved particle swarm optimization based mppt strategy for pv system ", MATEC Web of Conferences 139, 2014.

[20] L. L. Jiang, D. R. Nayanasiri, D. L. Maskell, and D. M. Vilathgamuwa, "A simple and efficient hybrid maximum power point tracking method for PV systems under partially shaded condition," in Proceedings of the 39th Annual Conference of the IEEE Industrial Electronics Society (IECON '13), pp. 1513-1518, Vienna, Austria, November 2013.

[21] L. M. Elobaid, A. K. Abdelsalam, and E. E. Zakzouk, "Artificial neural network based maximum power point tracking technique for PV systems," in Proceedings of the 38th Annual Conference on IEEE Industrial Electronics Society (IECON '12), pp. 937-942, IEEE, Montreal, Canada, October 2014.

[22] R. Ramaprabha, B. L. Mathur, and M. Sharanya, "Solar array modeling and simulation of MPPT using neural network," in Proceedings of the International Conference on Control Automation, Communication and Energy Conservation (INCACEC '09), pp. 1-5, IEEE, Perundurai, India, June 2009.

[23] S. D. Anitha and S. B. J. Prabha, "Artificial Neural Network based maximum power point tracker for photovoltaic system,” journal of solar energy, pages 20, 2016.

[24] A. Iqbal, H. Abu-Rub and S.M. Ahmed, "Adaptive neuro-fuzzy inference system based MPPT of a solar PV module," in proceedings of IEEE International Energy Conference and Exhibition (Energy Con '10), pp. 51-56, December 2014.

[25] C.S. Chiu and Y.L. Ouyang, "Robust maximum power tracking control of uncertain photovoltaic systems: a unified T-S fuzzy model-based approach," IEEE Transactions on Control Systems Technology, vol. 19, no. 6, pp. 1516-1526, 2015.

[26] Khaled Bataineh and Yazan Taamneh, "adaptive neuro - fuzzy inference system based improvement of P \& O MPPT technique for photovoltaic systems," international journal of power electronics and drives system (IJPEDS '17), pp.1327-1334, IEEE, Coimbatore, India, July 2017.

[27] R. Vinifa and A. Kavitha "maximum power point tracking of boost converter on a PV system using fuzzy logic" International journal of mechanical engineering and technology (IJMET), Vol 8, pp.584 593, December 2017.

[28] Unal Yilmaz, Ali Kiracy and Selim Borekci "PV system fuzzy logic MPPT method and PI control as a charge controller", Renewable and sustainable Energy Reviews, Vol 81, January 2018, pp.994-1001. 
International Journal of Control and Automation Vol. 12, No. 12 (2019) 